\title{
A standardized method for sampling and extraction methods for quantifying microplastics in beach sand
}

\author{
Aiken Besley ${ }^{\mathrm{a}}$, Martina G. Vijver ${ }^{\mathrm{b}}$, Paul Behrens ${ }^{\mathrm{a}, \mathrm{b}}$, Thijs Bosker ${ }^{\mathrm{a}, \mathrm{b}, *}$ \\ a Leiden University College, Leiden University, P.O. Box 13228, 2501 EE The Hague, The Netherlands \\ ${ }^{\mathrm{b}}$ Institute of Environmental Sciences, Leiden University, P.O. Box 9518, 2300 RA Leiden, The Netherlands
}

\section{A R T I C L E I N F O}

\section{Article history:}

Received 13 July 2016

Received in revised form 19 August 2016

Accepted 22 August 2016

Available online 7 September 2016

\section{Keywords:}

Microplastics

Beach sampling

Extraction

Method standardization

Standard operating procedure

\begin{abstract}
A B S T R A C T
Microplastics are ubiquitous in the environment, are frequently ingested by organisms, and may potentially cause harm. A range of studies have found significant levels of microplastics in beach sand. However, there is a considerable amount of methodological variability among these studies. Methodological variation currently limits comparisons as there is no standard procedure for sampling or extraction of microplastics. We identify key sampling and extraction procedures across the literature through a detailed review. We find that sampling depth, sampling location, number of repeat extractions, and settling times are the critical parameters of variation. Next, using a case-study we determine whether and to what extent these differences impact study outcomes. By investigating the common practices identified in the literature with the case-study, we provide a standard operating procedure for sampling and extracting microplastics from beach sand.
\end{abstract}

(c) 2016 Elsevier Ltd. All rights reserved.

\section{Introduction}

Human plastic consumption has increased at a dramatic rate over the last decades. In 1979, global plastic consumption was estimated to be 62 million tonnes, which increased to 160 million tonnes by 2000 (Pardos Marketing, 2006). More recently, global production rose $4 \%$ between 2013 and 2014, from 299 million tonnes to 311 million tonnes (Plastics Europe, 2015). A significant proportion of this plastic enters the environment; Jambeck et al. (2015) estimated it to be over 8 million tonnes of plastic enter the marine environment annually. As of 2014, it has been estimated that between 15 and 51 trillion particles, weighing up to 236,000 tons have accumulated in marine systems (van Sebille et al., 2015). One subgroup of emerging concern are small pieces of plastic, termed "microplastics" (Thompson et al., 2004). These are further subdivided into two groups. Primary microplastics are purposefully produced as micron-sized particles, and secondary microplastics are fragments from the breakdown of larger plastic debris. Due to the longevity of plastics, their fragmentation and accumulation in the environment have been considered as one of the most profound and longlasting recent changes to the Earth's surface (Barnes et al., 2009). The small size of microplastics make them available to both vertebrates and invertebrates. Microplastic ingestion has been observed in a wide variety of organisms, including zooplankton (Cole et al., 2013;

\footnotetext{
* Corresponding author.

E-mail addresses: Aiken12@hotmail.com (A. Besley), vijver@cml.leidenuniv.nl (M.G. Vijver), p.a.behrens@luc.leidenuniv.nl (P. Behrens), t.bosker@luc.leidenuniv.nl (T. Bosker).
}

Desforges et al., 2015; Setala et al., 2014), filter feeders, such as oysters and mussels (Cole and Galloway, 2015; Van Cauwenberghe et al., 2015a; Van Cauwenberghe and Janssen, 2014), and fish (Lusher et al., 2013; Mazurais et al., 2015).

There is a growing body of literature investigating microplastic pollution on beaches, including industrial plastic beads or granules, plastic fragments, and plastic fibres (Van Cauwenberghe et al., 2015b). While many studies identify the presence of microplastics in the environment, there remain large inconsistencies in their sampling, extraction, and consequent quantification (Shim and Thompson, 2015). Another recent study emphasized the inconsistency in microplastic sampling and extraction techniques, and stressed how current studies are often incomparable as a result (Van Cauwenberghe et al., 2015b). This variation in sampling and extraction processes throughout the scientific literature can potentially prevent comparison across studies (Cole et al., 2011). The variation makes it difficult to perform spatial and temporal distribution analysis, limiting our understanding of the overall microplastic pollution on beaches. This is particularly apparent with studies quantifying microplastics in beach sand, as shown in a recent methodological review (Hidalgo-Ruz et al., 2012). For example, there is considerable variation in the maximum depth during sampling. A number of studies sample the top $1 \mathrm{~cm}$ of sand alone (Baztan et al., 2014; Liebezeit and Dubaish, 2012). Others sample the top $5 \mathrm{~cm}$ (Heo et al., 2013; McDermid and McMullen, 2004). Due to the current lack of knowledge regarding transportation of microplastics, the different depths used for sampling may determine the abundances recorded. Furthermore, there is an overt problem of varying units throughout the literature (Van Cauwenberghe et al., 2015b). Microplastics have been reported 
as a quantity per area (Hidalgo-Ruz and Thiel, 2013), per volume (Baztan et al., 2014) and per weight (Dekiff et al., 2014). Although conversions are sometimes possible, the density of the sampled sand may have to be estimated, and if wet weight is used it cannot be compared with dry weight.

Similarly, there are differences in extraction procedures of plastics from beach samples. Although studies generally follow a similar method of extraction by flotation in a dense salt solution (Thompson et al., 2004), a number of parameters within this process vary greatly, or are not defined. Furthermore, a review of 44 studies on beach sand microplastic quantification revealed that the stirring and settling times defined for microplastic extraction varied widely. Similarly, the filtration process, including extracting the supernatant, was frequently unspecified (Hidalgo-Ruz et al., 2012). While some studies mention repeat extractions to improve extraction effectiveness, in most studies this is not included (Browne et al., 2011; Claessens et al., 2011).

In addition to the methodological inconsistencies, there has been a lack of consensus regarding the size range of microplastics. The European Marine Strategy Framework Directive (EMSFD) suggests that the upper bound for microplastic size should be plastic items $<5 \mathrm{~mm}$ in their largest dimension (Galgani et al., 2013). Although many studies do identify microplastics as plastic material $<5 \mathrm{~mm}$, they do not specify dimension sizes, leaving definitional ambiguity (Baztan et al., 2014; Galgani et al., 2013; Heo et al., 2013; Liebezeit and Dubaish, 2012; Martins and Sobral, 2011). Several studies consider $1 \mathrm{~mm}$ to be the maximum size, and generally they also omit dimension sizes (Browne et al., 2011; Claessens et al., 2011; Dekiff et al., 2014; Van Cauwenberghe et al., 2013; Vianello et al., 2013).

To overcome the lack of comparability between quantitative studies on microplastics on beaches and to allow cross-examination, our study aims to provide guidance to develop a standardized methodology for microplastic sampling and extraction. This work consists of three parts: firstly, we perform a detailed literature review to identify key differences in beach microplastic sampling and extraction procedures; secondly, in order to determine whether these differences impact study outcomes a case study at Meijendel beach (the Netherlands) is performed; finally, we synthesise our findings and provide a standard operating procedure for future beach microplastic investigations.

\section{Materials and methods}

\subsection{Literature review}

A detailed literature review was conducted to identify key methodological procedures in need of standardization in both sampling and extraction of beach sand. Only primary studies assessing microplastic pollution (or equivalent) in beach sand were considered. Studies included were peer-reviewed and published up until 31/12/14. Searches were made with Web of Science [v5.19] using the following keywords: "microplastic pollution", "microplastics beach", "microplastics beaches", "microplastics sediment", "plastic fragments beaches", "plastic debris beaches", and "plastic fragments sediment". A total of 22 studies were identified as meeting the selection criteria (Table 1).

We split the findings into sampling procedures and extraction procedures. Data regarding the variability in sampling procedures included: microplastic size definition, beach zones sampled, sample size, and sample depth. Data regarding variability in extraction procedures included: sample drying temperature/duration, settling time, number of repeat extractions, and quantitative units. The sampling and extraction procedures were then analysed and compared in terms of methodological variability.

\subsection{Case-study}

The case-study design was dependent on the findings of this literature review. As such, we list the key findings here, and outline findings further in the results section. In order to determine whether and to what magnitude these literature-identified variations in sampling and extraction procedures influenced study outcomes, a case-study was conducted in Meijendel, the Netherlands (Fig. 1). The predominate direction of the current near the beach is north-eastwards along the coast, while the predominant wind direction is southwest. Sand was collected at the

Table 1

Summary on sampling and extraction methodology used in beach sand sampling.

\begin{tabular}{|c|c|c|c|c|c|c|c|c|c|c|}
\hline \multirow[b]{2}{*}{ Location } & \multirow[b]{2}{*}{ Study references } & \multirow{2}{*}{$\frac{\text { Size }}{\text { definition }}$} & \multicolumn{3}{|l|}{ Sampling } & \multicolumn{5}{|l|}{ Extraction } \\
\hline & & & $\begin{array}{l}\text { Beach } \\
\text { zone }^{a} 2 b\end{array}$ & $\mathrm{n}$ & $\begin{array}{l}\text { Sampling } \\
\text { depth } \\
(\mathrm{cm})\end{array}$ & $\begin{array}{l}\text { Drying } \\
\text { duration/Temp } \\
\left({ }^{\circ} \mathrm{C}\right)\end{array}$ & $\begin{array}{l}\text { Extraction } \\
\text { process }\end{array}$ & $\begin{array}{l}\text { Stirring time } \\
(\mathrm{min}) / \text { speed } \\
(\mathrm{rpm})\end{array}$ & $\begin{array}{l}\text { Settling } \\
\text { time } \\
(\mathrm{min})\end{array}$ & $\begin{array}{l}\text { Repeat } \\
\text { extractions }\end{array}$ \\
\hline UK & Thompson et al. (2004) & $\mathrm{N} / \mathrm{D}$ & ITA & $\mathrm{N} / \mathrm{D}$ & $\mathrm{N} / \mathrm{D}$ & $\mathrm{N} / \mathrm{D} / \mathrm{N} / \mathrm{D}$ & Flotation & $0.5 \mathrm{~min} / \mathrm{N} / \mathrm{D}$ & 2 & $\mathrm{~N} / \mathrm{D}$ \\
\hline Hawaii & McDermid and McMullen (2004) & $1-15 \mathrm{~mm}$ & HTL/SLZ & 2 & 5.5 & $\mathrm{~N} / \mathrm{D} / \mathrm{N} / \mathrm{D}$ & Flotation & 1 / manually & $\mathrm{N} / \mathrm{D}$ & $\mathrm{N} / \mathrm{D}$ \\
\hline Singapore & $\mathrm{Ng}$ and Obbard (2006) & $\mathrm{N} / \mathrm{D}$ & HTL & $4-8$ & $1,10-11$ & $\mathrm{~N} / \mathrm{D} / \mathrm{N} / \mathrm{D}$ & Flotation & $1 / 200$ & 360 & 3 \\
\hline India & Reddy et al. (2006) & $\mathrm{N} / \mathrm{D}$ & ITA & 10 & 5 & $\mathrm{~N} / \mathrm{D} / \mathrm{N} / \mathrm{D}$ & Flotation & $60-120 / \mathrm{N} / \mathrm{D}$ & 15 & $\mathrm{~N} / \mathrm{D}$ \\
\hline Brasil & Costa et al. (2010) & $\leq 1 \mathrm{~mm}$ & HTL & 9 & 2 & Overnight/100 & Sieving only & $\mathrm{N} / \mathrm{A}$ & $\mathrm{N} / \mathrm{A}$ & $\mathrm{N} / \mathrm{A}$ \\
\hline Portugal & Frias et al. (2010) & $<5 \mathrm{~mm}$ & HTL & $\mathrm{N} / \mathrm{D}$ & 2 & $\mathrm{~N} / \mathrm{D} / \mathrm{N} / \mathrm{D}$ & Flotation & $\mathrm{N} / \mathrm{D} / \mathrm{N} / \mathrm{D}$ & $\mathrm{N} / \mathrm{D}$ & $\mathrm{N} / \mathrm{D}$ \\
\hline UK & Browne et al. (2010) & $<1 \mathrm{~mm}$ & HTL & 30 & 3 & $\mathrm{~N} / \mathrm{D} / \mathrm{N} / \mathrm{D}$ & Flotation & $\mathrm{N} / \mathrm{D} / \mathrm{N} / \mathrm{D}$ & $\mathrm{N} / \mathrm{D}$ & $\mathrm{N} / \mathrm{D}$ \\
\hline Belgium & Claessens et al. (2011) & $\leq 1 \mathrm{~mm}$ & HTL/ITA & $\mathrm{N} / \mathrm{D}$ & $\mathrm{N} / \mathrm{D}$ & $\mathrm{N} / \mathrm{D} / \mathrm{N} / \mathrm{D}$ & Flotation & $1 / \mathrm{N} / \mathrm{D}$ & 60 & 2 \\
\hline Malta & Turner and Holmes (2011) & $\mathrm{N} / \mathrm{D}$ & Random & $11-29$ & $\mathrm{~N} / \mathrm{D}$ & $\mathrm{N} / \mathrm{D} / \mathrm{N} / \mathrm{D}$ & Sieving only & $\mathrm{N} / \mathrm{A}$ & $\mathrm{N} / \mathrm{A}$ & $\mathrm{N} / \mathrm{A}$ \\
\hline Portugal & Martins and Sobral (2011) & $\leq 5 \mathrm{~mm}$ & HTL & 6 & 2 & $\mathrm{~N} / \mathrm{D} / \mathrm{N} / \mathrm{D}$ & Flotation & $\mathrm{N} / \mathrm{D} / \mathrm{N} / \mathrm{D}$ & $\mathrm{N} / \mathrm{D}$ & $\mathrm{N} / \mathrm{D}$ \\
\hline Germany & Liebezeit and Dubaish (2012) & $<5 \mathrm{~mm}$ & $\mathrm{~N} / \mathrm{D}$ & $13-15$ & 1 & $\mathrm{~N} / \mathrm{D} / 70$ & Flotation & $\mathrm{N} / \mathrm{D} / \mathrm{N} / \mathrm{D}$ & $\mathrm{N} / \mathrm{D}$ & 3 \\
\hline Chile & Hidalgo-Ruz and Thiel (2013) & $<1 \mathrm{~mm}$ & HTL & 6 & 2 & $\mathrm{~N} / \mathrm{D} / \mathrm{N} / \mathrm{D}$ & Sieving only & $\mathrm{N} / \mathrm{A}$ & $\mathrm{N} / \mathrm{A}$ & $\mathrm{N} / \mathrm{A}$ \\
\hline South Korea & Heo et al. (2013) & $<5 \mathrm{~mm}$ & $\mathrm{HTL} / \mathrm{CS}$ & $10-49$ & 5 & $\mathrm{~N} / \mathrm{D} / \mathrm{N} / \mathrm{D}$ & Sieving only & $\mathrm{N} / \mathrm{A}$ & $\mathrm{N} / \mathrm{A}$ & $\mathrm{N} / \mathrm{A}$ \\
\hline India & Jayasiri et al. (2013) & $<5 \mathrm{~mm}$ & HTL & 3 & 2 & $\mathrm{~N} / \mathrm{D} / \mathrm{N} / \mathrm{D}$ & Flotation & $\mathrm{N} / \mathrm{D} / \mathrm{N} / \mathrm{D}$ & $\mathrm{N} / \mathrm{D}$ & $\mathrm{N} / \mathrm{D}$ \\
\hline Italy & Vianello et al. (2013) & $\leq 1 \mathrm{~mm}$ & $\mathrm{~N} / \mathrm{A}$ & 2 & $0-5$ & $\mathrm{~N} / \mathrm{D} / 90$ & Flotation & 1.5 / N/D & 60 & 3 \\
\hline Brasil & Fisner et al. (2013) & $\mathrm{N} / \mathrm{D}$ & SLZ & 10 & $0-100^{\mathrm{b}}$ & $\mathrm{N} / \mathrm{D} / \mathrm{N} / \mathrm{D}$ & Flotation & N/D / N/D & $\mathrm{N} / \mathrm{D}$ & $\mathrm{N} / \mathrm{D}$ \\
\hline Canary Islands & Baztan et al. (2014) & $<5 \mathrm{~mm}$ & HTL & $35-88$ & 1 & $\mathrm{~N} / \mathrm{D} / \mathrm{N} / \mathrm{D}$ & On-site flotation & $\mathrm{N} / \mathrm{D} / \mathrm{N} / \mathrm{D}$ & $\mathrm{N} / \mathrm{D}$ & $\mathrm{N} / \mathrm{D}$ \\
\hline Norderney & Dekiff et al. (2014) & $<5 \mathrm{~mm}$ & HTL & 12 & 3 & $\mathrm{~N} / \mathrm{D} / 60$ & Flotation & $\mathrm{N} / \mathrm{D} / \mathrm{N} / \mathrm{D}$ & $\mathrm{N} / \mathrm{D}$ & $\mathrm{N} / \mathrm{D}$ \\
\hline Canada & Mathalon and Hill (2014) & $<5 \mathrm{~mm}$ & HTL/MTL/LTL & $\mathrm{N} / \mathrm{D}$ & $3-4$ & $\mathrm{~N} / \mathrm{D} / 65.5$ & Flotation & $1-2 / N / D$ & 3-6 min. & 2 \\
\hline Canada & Castaneda et al. (2014) & $<5 \mathrm{~mm}$ & $\mathrm{~N} / \mathrm{A}$ & 6 & 10 & $\mathrm{~N} / \mathrm{D} / \mathrm{N} / \mathrm{D}$ & Sieving only & $\mathrm{N} / \mathrm{A}$ & $\mathrm{N} / \mathrm{A}$ & $\mathrm{N} / \mathrm{A}$ \\
\hline Romania & Popa et al. (2014) & $\mathrm{N} / \mathrm{D}$ & $\mathrm{N} / \mathrm{D}$ & 3 & $\mathrm{~N} / \mathrm{D}$ & $\mathrm{N} / \mathrm{D} / \mathrm{N} / \mathrm{D}$ & Flotation & N/D / N/D & $\mathrm{N} / \mathrm{D}$ & 3 \\
\hline Slovenia & Laglbauer et al. (2014) & $<5 \mathrm{~mm}$ & HTL/ITA & 3 & 5 & $24 \mathrm{~h} / 100$ & Flotation & 2/manually & 30 & 2 \\
\hline
\end{tabular}

${ }^{a}$ HTL = High Tide Line (including shore line and tidal mark), MTL: Mid Tide Line, LTL = Low Tide Line, ITA = Intertidal area, SL = Shoreline, SLZ: Suppralittoral zone, CS: Cross section b In $10 \mathrm{~cm}$ bands. 


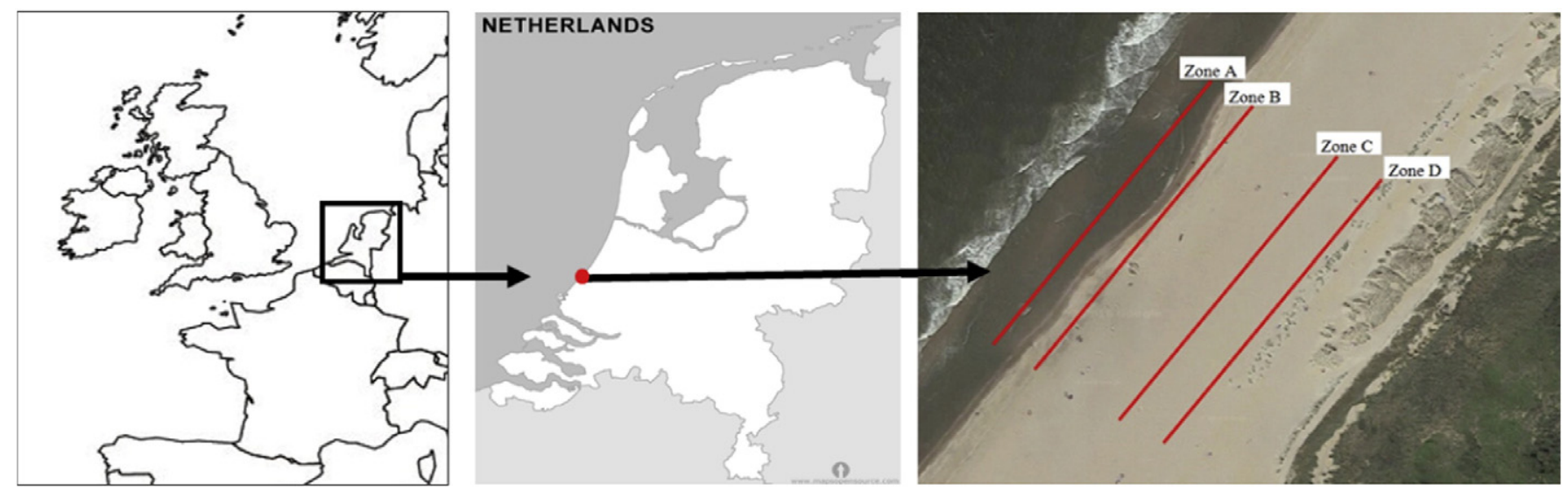

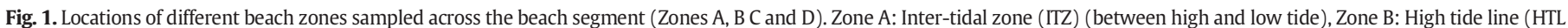
(line of deposition from high tide), Zone C: supralittoral zone 1 (SLZ30) (30 m from dunes), Zone D: Supralittoral zone 2 (SLZ15) (15 m from dunes).

(Source: Google Maps. Inset: Netherlands and Northern-western Europe)

high tide line of Meijendel beach, the Netherlands (Fig. 1) in the spring of 2015 and 2016. Random samples were collected at the beach in four zones over a $100 \mathrm{~m}$ stretch (Fig. $1: n=10$ samples per zone, total of 40 samples). Sampling was conducted using a sampling quadrat of $50 \times 50$ $\mathrm{cm}$, which was placed at the sampling location. Next, a metallic spoon was used to collect sand from the top $5 \mathrm{~cm}$ (measured with a metallic ruler) in the four corners of the sampling quadrat, as well as the centre. The sand was then put through a $5 \mathrm{~mm}$ metallic sieve and stored in a plastic sealed container, which was rinsed in the laboratory prior to use. Between sampling, the materials were rinsed using seawater. In addition, on four sites additional depth samples were taken ( 4 depths/site for a total of 16 samples). Sand was transported back to the laboratory, dried, and kept at room temperature until extraction.

To extract the microplastics, a fully-saturated salt solution was prepared by dissolving $358.9 \mathrm{~g}$ of $\mathrm{NaCl}$ in $1 \mathrm{~L}$ of demineralized water (water density of $9043 \mathrm{~kg} / \mathrm{m}^{3}$ at $20^{\circ} \mathrm{C}$ ). This solution was stirred for $48 \mathrm{~h}$ at $600 \mathrm{rpm}$ at $60{ }^{\circ} \mathrm{C}$. The salt-solution was left to cool down, and then filtered to remove impurities using $47 \mathrm{~mm}$ Millipore $0.45 \mu \mathrm{m}$ filter papers (Fisher scientific, the Netherlands). Filtration of the salt-solution is key, as a previous study found microplastic pollution in table salt (Yang et al., 2015). Extraction of microplastics was achieved by density separation. Dry sand was combined with saturated salt solution (ratio of $100 \mathrm{~g}$ dried sand in $400 \mathrm{~mL}$ of salt-solution) and stirred with a magnetic stirrer for $2 \mathrm{~min}$ at $600 \mathrm{rpm}$. The supernatant was carefully poured into a vacuum filtration system (Thermo Scientific Nalgene, the Netherlands) and filtered through $47 \mathrm{~mm}$ Millipore $0.45 \mu \mathrm{m}$ filter papers. The filter papers were then examined under stereo-microscopes at up to $40 \times$ magnification and microplastics were systematically counted, which allows for quantification of microplastics in the range of $0.3-5 \mathrm{~mm}$ (NOAA, 2015). Based on the most commonly used definition in the literature review, microplastics were defined as plastic material smaller than $5 \mathrm{~mm}$ in their largest dimension. To assess laboratory contamination we also ran a blank. This involved using $200 \mathrm{~mL}$ of filtered, saturated salt solution without sand, following the identical procedure detailed above. This was repeated for each set of extractions, thereby offering a quantification of contamination.

We split our investigations into methodological variation by sampling and extraction procedures.

\subsubsection{Investigating sampling procedures}

Optimal sampling depth: Sand samples were taken at depths of 1,2, 5 and $10 \mathrm{~cm}$. A metallic ruler was used to control the depth during sampling. A sample was taken for each depth at four different locations on the beach $\left(3 \mathrm{~m}, 14 \mathrm{~m}, 20 \mathrm{~m}\right.$ and $32 \mathrm{~m}$ from a reference location of $52^{\circ}$ $\left.08^{\prime} 29.0^{\prime \prime} \mathrm{N}, 4^{\circ} 19^{\prime} 15.6^{\prime \prime} \mathrm{E}\right)$.
Sample size per $100 \mathrm{~m}$ stretch: To determine the impact of sample size (n) on the precision of the mean, expressed as confidence interval around the mean $(d)$, a statistical analysis was performed. We expressed $d$ in units of standard deviation of the sample (s). To determine the sample size needed for different confidence intervals and at different confidence levels $[\alpha=0.90(Z=1.65), \alpha=0.95(Z=1.96)$ and $\alpha=0.99(Z=2.56)]$ the following equation was used, based on normal distribution:

$n=\frac{s^{2} Z^{2}}{d^{2}}$

Next, using the data collected in the case study we visualized the impacts of sample size on the confidence interval around the mean (d) at different sample sizes ( $\mathrm{n}$ ranged from 2 to 40 ) by rearranging formula (1):

$d=\frac{s Z}{\sqrt{n}}$.

Optimal beach sampling location: Sand samples were taken from four different areas of a beach segment (Fig. 1), ranging from the high-tide line to the supralittoral zone. From each zone ten sand samples were taken at $3 \mathrm{~m}, 14 \mathrm{~m}, 20 \mathrm{~m}, 32 \mathrm{~m}, 41 \mathrm{~m}, 45 \mathrm{~m}, 50 \mathrm{~m}, 59 \mathrm{~m}$, $77 \mathrm{~m}$ and $98 \mathrm{~m}$ from a reference location $\left(52^{\circ} 08^{\prime} 29.0^{\prime \prime} \mathrm{N}, 4^{\circ} 19^{\prime} 15.6^{\prime \prime} \mathrm{E}\right)$. GPS coordinates of the sampling sites are shown in supplementary information (Supplementary Table 1).

\subsubsection{Investigating extraction procedures}

Drying duration: the time required to fully dry $250 \mathrm{~g}$ of wet weight sand (collected at the high tide line) in an oven at $60^{\circ}$ was quantified. The weight of sand samples was measured after $0,24,48$ and $72 \mathrm{~h}$ of drying. Three sand samples were used to account for moisture variation.

Settling time: After stirring $50 \mathrm{~g}$ of sample beach sand in $200 \mathrm{~mL}$ of fully saturated saline solution for $2 \mathrm{~min}$ at $600 \mathrm{rpm}$, visual observations about the clarity of the extracts (or solutions) were conducted hourly. A control with $200 \mathrm{~mL}$ of the same saline solution without sand was used as a control.

Number of repeat extractions: to quantify the number of microplastics, 6 samples were extracted five consecutive times per sample. The number of microplastics counted for each extraction was recorded. 
Table 2

Definition of size dimensions of microplastics in beach sand (based on literature review; $n$ $=22$ peer-reviewed studies).

\begin{tabular}{ll}
\hline Definition of microplastics & Number of studies \\
\hline$\leq 1 \mathrm{~mm}$ & 5 \\
$\leq 5 \mathrm{~mm}$ & 10 \\
$\leq 15 \mathrm{~mm}$ & 1 \\
No clear definition & 6 \\
Inclusion of dimensions (other than default definitions) & 1 \\
\hline
\end{tabular}

Table 3

Sampling locations on the beach (based on literature review; $\mathrm{n}=22$ peer-reviewed studies).

\begin{tabular}{ll}
\hline Sampling location & Number of studies $^{\mathrm{a}}$ \\
\hline Low tide line & 1 \\
Intertidal zone & 5 \\
High tide line & 14 \\
Supralittoral zone & 2 \\
Not defined & 1 \\
Not applicable & 2 \\
\hline
\end{tabular}

a Multiple locations were sampled in a total of 5 studies, therefore the number of studies exceeds 22 .

\subsection{Statistical approaches}

Statistical analysis was conducted using XLSTAT-Base with a significance level set at $\alpha \leq 0.05$. Statistical analysis, in the form of a KruskalWallis test, two-way analysis of variance (ANOVA) was applied to sampling location and sampling depth data. The presence of distributional differences in microplastic abundance across the beach zones, and among different sample depths was tested. The non-parametric, pairwise Dunn test was used to reveal any significantly differing groups. Non-parametric tests were chosen due to the small sample size for each beach zone and depth variable.

\section{Results}

\subsection{Literature review}

There was a significant amount of variation in sampling procedures across studies (Table 1). The definition of a microplastic varied across studies, with five studies defining a microplastic as $<1 \mathrm{~mm}$ and ten studies as $<5 \mathrm{~mm}$ (Table 2). Interestingly, six out of 22 studies did not provide a clear definition of a microplastic, and only one out of the 22 studies provided information on the dimensions (Table 2). The sampling location at the beach also varied among studies, with the high tide line being the most common beach zone to sample (Table 3 ). Of the 22 studies, 12 sampled at or near the high tide line, strandline or shoreline, while four studies sampled in the intertidal area, and only two studies sampled in the supralittoral zone (Table 3). Five studies sampled at multiple locations on the beach (Table 3 ).

Sampling depth varied greatly among studies: the majority of studies sampled the top $2 \mathrm{~cm}$ or top $3-5 \mathrm{~cm}$ of the beach, with only two

Table 4

Sampling depth during beach sampling for microplastics (based on literature review; $n=22$ peer-reviewed studies).

\begin{tabular}{ll}
\hline Sampling depth & Number of studies \\
\hline Top $1 \mathrm{~cm}$ & 2 \\
Top $2 \mathrm{~cm}$ & 5 \\
Top $3-5 \mathrm{~cm}$ & 5 \\
Top $6-10 \mathrm{~cm}$ & 2 \\
Not defined & 3 \\
Range of sampling depths & 3 \\
\hline
\end{tabular}

\section{Table 6}

Drying time and drying duration of beach sand samples (based on literature review; $n=22$ peer-reviewed studies).

\begin{tabular}{ll}
\hline Drying time & Number of studies \\
\hline Overnight & 1 \\
24 h & 1 \\
Not defined & 20 \\
& \\
Drying temperature & Number of studies \\
$60-70$ & 4 \\
$71-80$ & 0 \\
$81-90$ & 1 \\
$91-100$ & 1 \\
Not defined & 16 \\
\hline
\end{tabular}

Table 5

Number of replicate samples taken to determine loads of microplastics in beach sand (based on literature review; $\mathrm{n}=22$ peer-reviewed studies).

\begin{tabular}{ll}
\hline Number of replicate samples & Number of studies $^{\text {a }}$ \\
\hline $1-3$ & 5 \\
$4-6$ & 3 \\
$7-9$ & 2 \\
$10-12$ & 3 \\
$>12$ & 5 \\
Not defined & 4 \\
\hline
\end{tabular}

a In some studies a range of sample sizes were used, in which case the highest sample size was used in this table.

studies sampling the top $1 \mathrm{~cm}$ or top $6-10 \mathrm{~cm}$ of the beach (Table 4$)$. Importantly, four studies did not define sampling depth within their study. Noticeably, the number of samples taken from one beach varied greatly, from 2 to up to 88 (Table 5), while four studies did not provide the sample size within their study.

During the extraction phase there was also a significant amount of variation among procedures (Table 1 ). The majority of studies (17 out of 22) used flotation to extract and quantify microplastics. In the other five studies, the samples were first sieved, followed by visual assessment, in most cases with a microscope. The duration of drying per sample was not provided for the majority of studies (20 out of 22) and when provided it ranged from 12 to $24 \mathrm{~h}$ (Table 6). This is important as most studies expressed the number of microplastics per volume or weight of sand, and the wetness of the sand can influence the outcomes. The settling time after stirring the sand/salt-solution was not defined in 10 studies. In studies where it was defined, it ranged from $30 \mathrm{~s}$ to $6 \mathrm{~h}$ (Table 7). The settling time determines the extent of material obtained in the filtration process. With short settling times the separation process is less effective as dense material obscures microscope identification of microplastics. The number of repeat extractions was not reported in 10 of the studies which conducted separation by flotation, while three studies each conducted 2 or 3 repeat extractions (Table 8).

\subsection{Case-study}

The blanks used in the study resulted in limited background contamination. On average, there were $3.3+/-3.27$ microplastics found on the blanks.

Table 7

Settling time before extraction after stirring of sand/salt solution (based on literature review; $\mathrm{n}=22$ peer-reviewed studies).

\begin{tabular}{ll}
\hline Settling time & Number of studies \\
\hline$<30$ min & 3 \\
$30-60$ min & 3 \\
$>60$ & 1 \\
Not defined & 10 \\
Not applicable & 5 \\
\hline
\end{tabular}


Table 8

Number of repeat extractions used to quantify microplastic loads in beach sand (based on literature review; $\mathrm{n}=22$ peer-reviewed studies).

\begin{tabular}{ll}
\hline Number of repeat extractions & Number of studies \\
\hline 1 & 0 \\
2 & 3 \\
3 & 3 \\
Not defined & 10 \\
Not applicable & 5 \\
\hline
\end{tabular}

\subsubsection{Optimization of sampling procedure}

Sample size per $100 \mathrm{~m}$ stretch: Fig. 2A shows that if a confidence interval around the mean of 1 standard deviation is deemed sufficiently precise, a sample size of between 3 and 5 samples is needed, depending on the desired confidence level. Sample size increases rapidly with smaller confidence intervals. For example, a sample size of 11 is needed to reach a 0.5 standard deviation at a confidence interval and a confidence level of $90 \%$. This increases to 22 samples per $100 \mathrm{~m}$ stretch with a confidence level of 99\%. Fig. 2B shows that in our case-study the confidence interval around the mean at low sample sizes is large, but rapidly decreases after 5 samples per $100 \mathrm{~m}$ stretch.

Sampling depth: Microplastics were found in all samples at every depth (Table 9). There were clear differences among the mean number of microplastics in $50 \mathrm{~g}$ dry weight samples from different depths. Samples taken from the top $1 \mathrm{~cm}$ and $5 \mathrm{~cm}$ both had a mean of 23.5 microplastics per $50 \mathrm{~g}$ of sand, while samples from the top $2 \mathrm{~cm}$ and $10 \mathrm{~cm}$ had means of 13.0 and 12.5 microplastics per $50 \mathrm{~g}$ of sand respectively (Table 9). The variance across locations was high, however, statistical analysis found significant differences among samples from the four different depths (Kruskal-Wallis test, $\mathrm{k}=8.143, p=0.043$ ). Pairwise analysis identified significantly fewer microplastics in samples taken from the top $10 \mathrm{~cm}$, compared with samples from both $1 \mathrm{~cm}$ (Dunn procedure, $\mathrm{p}=0.04$ ) and $5 \mathrm{~cm}$ (Dunn procedure, $p=0.03$ ). No other pairwise differences were statistically significant $(p>0.05)$.

Sampling location at beach: Microplastics were found in all locations and no statistically significant differences identified between sampling locations were observed (Kruskal-Wallis test, $\mathrm{K}=2.048, p=0.563$; Table 10). The total number of microplastics identified ranged from 10 to 75 per $50 \mathrm{~g}$ sample (Table 10 ). This equates to $200-1500$ per $\mathrm{kg}$ of dry weight sand.

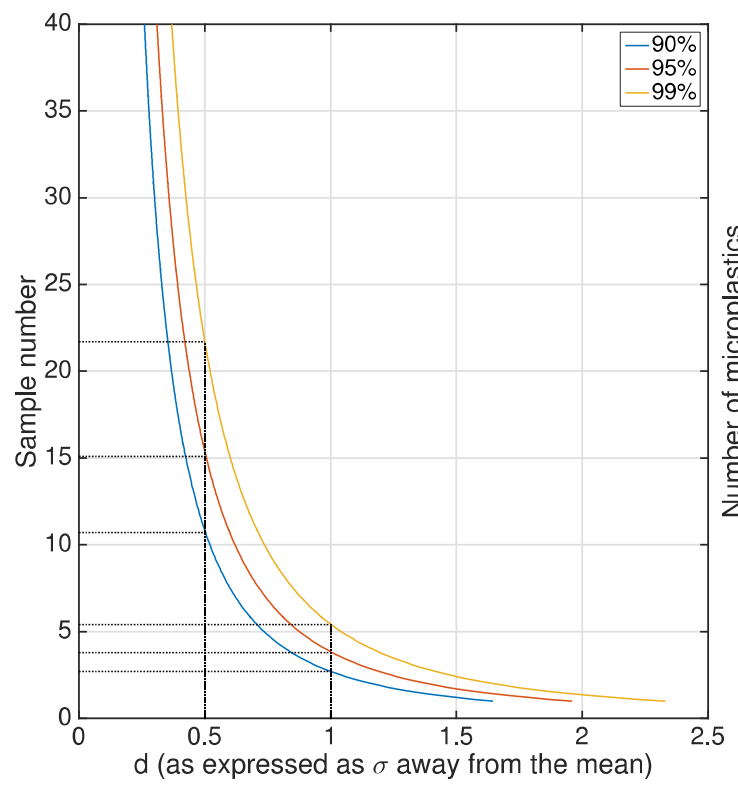

Table 9

Total number of microplastics observed from samples at depths of $1 \mathrm{~cm}, 2 \mathrm{~cm}, 5 \mathrm{~cm}$ and 10 $\mathrm{cm}$, from four sites at Meijendel beach.

\begin{tabular}{lllllll}
\hline & \multicolumn{7}{l}{ Total number of microplastics } \\
\cline { 2 - 7 } Sample depth & Site 1 & Site 2 & Site 3 & Site 4 & Mean & St. dev \\
\hline $1 \mathrm{~cm}$ & 38 & 23 & 17 & 16 & 23.5 & 10.1 \\
$2 \mathrm{~cm}$ & 12 & 21 & 10 & 9 & 13.0 & 5.5 \\
$5 \mathrm{~cm}$ & 17 & 36 & 21 & 20 & 23.5 & 8.5 \\
$10 \mathrm{~cm}$ & 8 & 16 & 14 & 12 & 12.5 & 3.4 \\
\hline
\end{tabular}

\subsubsection{Optimization of extraction protocol}

Drying duration: With an initial wet weight of $250 \mathrm{~g}$, the resultant sand dry weights differed by sample ( $225.2 \mathrm{~g}$ to $229.1 \mathrm{~g}$ ). A temperature of $60^{\circ} \mathrm{C}$ and a drying time of $48 \mathrm{~h}$ were required to reach dry weight. The majority of the weight reduction occurred within $24 \mathrm{~h}$. This suggests that a minimum drying time of $48 \mathrm{~h}$ at $60{ }^{\circ} \mathrm{C}$ is required to ensure no variation between samples.

Settling time: Hourly observations of the turbidity of solutions differed per sample and location. Only the sample from the intertidal zone was completely clear after $5 \mathrm{~h}$. Samples from the other sampling locations were observed as "almost clear" after $5 \mathrm{~h}$ (Supplementary Table 2). This suggests that a minimum of $5 \mathrm{~h}$ is required for beach sand salt-solutions to completely separate the microplastics from the sand particles.

Number of repeat extractions: Multiple extractions are needed to recover microplastics. Our results indicate that on average, only $30.2 \%$ (range 12.5-45\%) of microplastics were recovered after the first extraction, compared to a total of five extractions (Table 11). This percentage increases to $62.8 \%$ (range $47.1-76.5 \%$ ) after 2 extractions, $83.0 \%$ (range 70.6-94.1\%) after 3 extractions (Table 11). The 4th and 5th extraction yielded significantly less microplastics than the first three extractions, ranging from 0 to 5 plastics (Table 11). With 4 extractions, the percentage yield compared to 5 extractions was between 88.7 and $100 \%$, with a mean of $93.3 \%$ (Table 11 ).

\section{Discussion}

We found significant differences in sampling and extraction procedures across beach microplastic studies. In particular, the definition of microplastics, the sampling depth, sample size, sampling location, drying duration, settling time of the sand/salt solution, and the number of

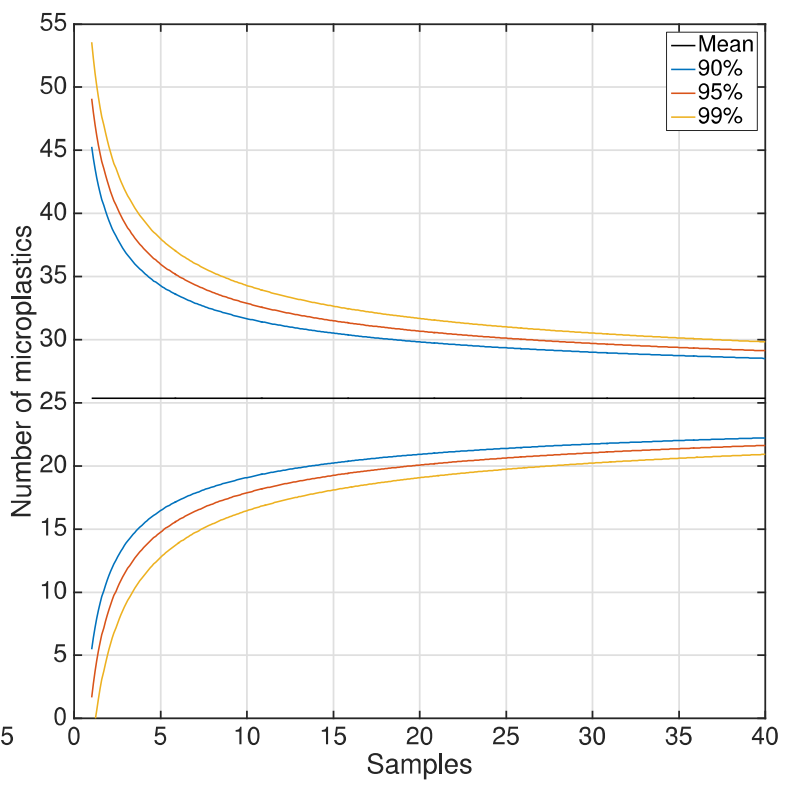

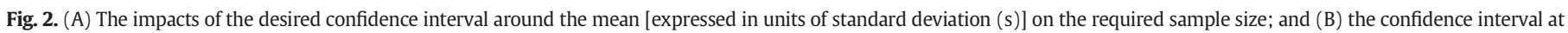
different sample size in the case-study conducted at Meijendel beach (The Hague, the Netherlands). 


\section{Table 10}

Number of microplastics per $50 \mathrm{~g}$ dry-weight beach sand from Meijendel beach, at the interidal zone (ITZ), high tidel line (HTL), and supralittoral zone at $30 \mathrm{~m} 30 \mathrm{~m}$ (SLZ-30) and $15 \mathrm{~m} 15 \mathrm{~m}$ (SLZ-15) from the dunes (see Fig. 1).

\begin{tabular}{|c|c|c|c|c|c|c|c|c|c|c|c|c|}
\hline \multirow{3}{*}{$\begin{array}{l}\text { Beach } \\
\text { zone }\end{array}$} & \multicolumn{12}{|c|}{ Number of microplastics per $50 \mathrm{~g}$ dry-sand } \\
\hline & \multicolumn{10}{|c|}{ Sample number } & \multirow[t]{2}{*}{ Mean } & \multirow[t]{2}{*}{ Std. dev. } \\
\hline & 1 & 2 & 3 & 4 & 5 & 6 & 7 & 8 & 9 & 10 & & \\
\hline ITZ & 13 & 21 & 24 & 32 & 31 & 75 & 20 & 13 & 34 & 28 & 29.10 & 17.75 \\
\hline HTL & 17 & 36 & 21 & 20 & 24 & 55 & 12 & 26 & 16 & 25 & 25.20 & 12.37 \\
\hline SLZ-30 & 17 & 23 & 23 & 20 & 22 & 18 & 24 & 28 & 22 & 16 & 21.30 & 3.62 \\
\hline SLZ-15 & 10 & 28 & 26 & 25 & 26 & 25 & 16 & 17 & 48 & 38 & 25.90 & 10.91 \\
\hline
\end{tabular}

repeat extractions are found to be either highly variable, or unspecified. The fact that different definitions of microplastics are used across studies makes comparison difficult. Our findings reiterate the difficulty of comparing across studies given the range in different sampling and extraction methods applied. Based on our literature review we suggest using the definition of microplastic items less than $5 \mathrm{~mm}$ in their largest dimension. This is in line with definition of the European Marine Strategy Framework Directive (EMSFD; Galgani et al., 2013), and is comparable to the definition by the National Oceanic and Atmospheric Administration (NOAA).

The variation in sampling depth and sampling location was seen in the secondary literature search and confirmed by our data collection. Importantly, our case-study indicated that location of sampling on the beach may not influence the overall outcomes of the results. Our findings are in line with previous studies, where no clear distributional pattern of microplastics at different sampling locations was found (Hidalgo-Ruz and Thiel, 2013; Mathalon and Hill, 2014). In addition, we found limited impact of sampling depth, with the exception of sampling the top $10 \mathrm{~cm}$ of the beach. To the best of our knowledge, this is the first study to compare loads of microplastics across different sampling depths. Our results indicate that research using samples from different depths within a 1 to $5 \mathrm{~cm}$ band remain comparable. Based on this study we advise sampling of the top $5 \mathrm{~cm}$ of sand, as is most commonly done across studies.

Our sampling results showed a relatively high variability across replicate samples. In addition, the literature found a high variability in the number of samples taken per $100 \mathrm{~m}$ stretch, ranging from 2 to 88 replicates, with the majority of studies taking 3 or less samples. Our analyses show that the confidence interval around the mean at low sample sizes is relatively high. Based on our data from the case-study the confidence interval around the mean was relatively high at low sample sizes, but when approaching 5 replicate samples, the confidence interval decreased rapidly. We therefore suggest that researchers conduct a sample size calculation using formula (1) before starting their assessment.

We did find significant impacts of extraction procedures on study outcomes, and thus comparability across studies. As identified, important aspects of the methodology, such as sand drying and settling time

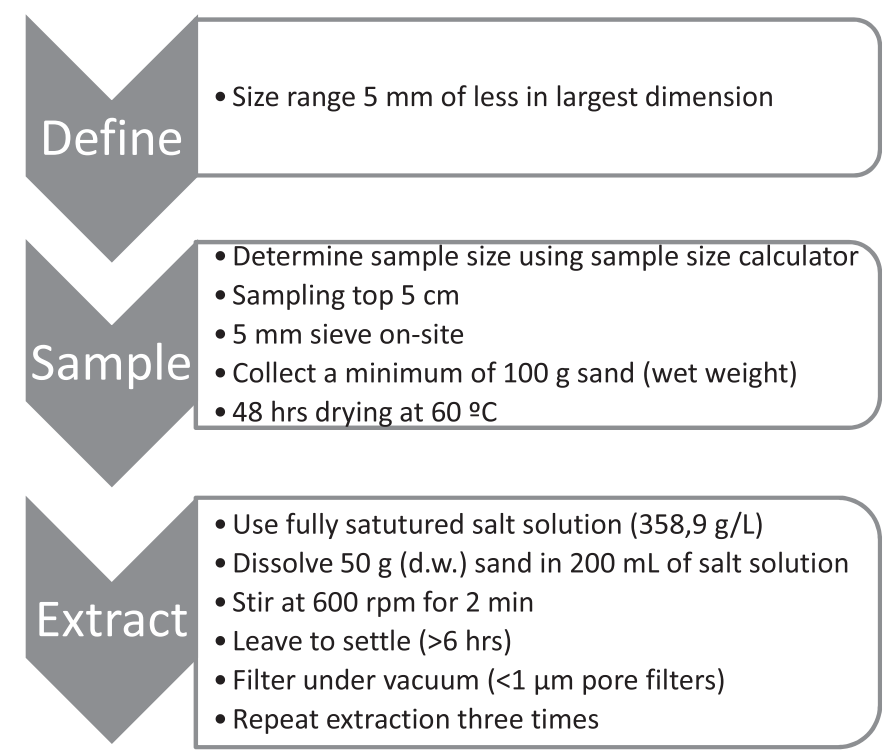

Fig. 3. SOP flowchart for sampling and extracting microplastics from beach sand.

for stirred sand solutions, are regularly unspecified. For example, a number of studies specify a settling time for stirred mixtures as under an hour (e.g. Thompson et al., 2004; Srinivasa Reddy et al., 2006; Mathalon and Hill, 2014). On the contrary, this study identifies that over $5 \mathrm{~h}$ is required for the settling process. In addition, repeat extractions can have a significant impact on the study outcomes. We found that a minimum of 3 repeat extractions are needed to recover $~ 80 \%$ of samples compared to 5 repeat extractions. These results differ from a study by Mathalon and Hill (2014), who found that the majority of microplastics were extracted after the first extraction.

In several studies additional steps are taken to differentiate between natural and chitin fragments or cellulose fibers, such as FT-IR or Raman spectroscopy (e.g. Thompson et al., 2004; Claessens et al., 2011), differential staining (e.g. with Nile Red; Andrady, 2010), gas chromatography with mass spectrometry (Dekiff et al., 2014), or pre-treatment with hydrogen peroxide (e.g. Mathalon and Hill, 2014; NOAA, 2015). No systematic review on these additional steps has been conducted to date, and future studies should focus on the impact of these steps on overall microplastic quantification.

Based on the outcomes of the literature review and the case-study we have developed a Standardized Operation Procedure for sampling and extracting microplastics from beach sand. The SOP is intended for studies with the objective of quantifying microplastics in beach sand, and was limited to standard laboratory equipment and resources. A flowchart outlining the key steps in this SOP is shown in Fig. 3; further details are given in the Supplementary Information.

Table 11

Microplastics counted from extraction filter papers, for 5 samples, with 5 repeat extractions. Including the percentage of total yielded from 1, 2, 3 and 4 extractions.

\begin{tabular}{|c|c|c|c|c|c|c|c|}
\hline \multirow[b]{2}{*}{ Extraction number } & \multicolumn{6}{|c|}{ Microplastics quantified per extraction } & \multirow{2}{*}{ Average } \\
\hline & Sample 1 & Sample 2 & Sample 3 & Sample 4 & Sample 5 & Sample 6 & \\
\hline 1 & 14 & 12 & 9 & 4 & 5 & 3 & 7.8 \\
\hline 2 & 7 & 8 & 5 & 9 & 3 & 14 & 7.7 \\
\hline 3 & 17 & 3 & 3 & 3 & 4 & 4 & 5.7 \\
\hline 4 & 1 & 5 & 2 & 1 & 4 & 1 & 2.3 \\
\hline 5 & 5 & 3 & 1 & 0 & 1 & 2 & 2.0 \\
\hline Total & 44 & 31 & 20 & 17 & 17 & 24 & 25.5 \\
\hline$\%$ from 1 extraction & $31.8 \%$ & $38.7 \%$ & $45.0 \%$ & $23.5 \%$ & $29.4 \%$ & $12.5 \%$ & $30.2 \%$ \\
\hline$\%$ from 2 extractions & $47.7 \%$ & $64.5 \%$ & $70.0 \%$ & $76.5 \%$ & $47.1 \%$ & $70.8 \%$ & $62.8 \%$ \\
\hline$\%$ from 3 extractions & $86.4 \%$ & $74.2 \%$ & $85.0 \%$ & $94.1 \%$ & $70.6 \%$ & $87.5 \%$ & $83.0 \%$ \\
\hline$\%$ from 4 extractions & $88.6 \%$ & $90.3 \%$ & $95.0 \%$ & $100.0 \%$ & $94.1 \%$ & $91.7 \%$ & $93.3 \%$ \\
\hline
\end{tabular}




\section{Conclusions}

A literature review on microplastics in beach sand found significant variation in sampling and extraction procedures. A case-study in Meijdendel, the Netherlands, found that sampling depth $(1-5 \mathrm{~cm})$ and sampling location have limited impact on the study outcomes. However, settling time and number of repeat extractions need to be standardized for comparison across studies. Our study results show an optimum recovery of $5 \mathrm{~h}$ of settling time and 3 repeated extractions. Based on the literature review and case-study, a Standard Operation Procedure (SOP) was developed in order to improve comparability between studies. The SOP is easy to perform and requires low amount of sophisticated equipment, enabling it to be easily used, and making it feasible for less developed countries and, even citizen science projects.

\section{Competing interests}

The authors declare that they have no competing interests.

\section{Funding}

TB, PB and MGV were funded by the Gratama Foundation of the Leiden University Fund (project number 2015-08).

\section{Acknowledgements}

We thank Abi Ashton and Ingrid Maya Alba Heller for the support collaboration during the project and other colleagues from Leiden University for helpful discussions.

\section{Appendix A. Supplementary data}

Supplementary data to this article can be found online at http://dx. doi.org/10.1016/j.marpolbul.2016.08.055.

\section{References}

Andrady, A.L., 2010. Measurement and occurrence of microplastics in the environment. Presentation at the 2nd Research Workshop on Microplastic Debris. Tacoma, WA, Nov 5-6, 2010.

Barnes, D.K.A., Galgani, F., Thompson, R.C., Barlaz, M., 2009. Accumulation and fragmentation of plastic debris in global environments. Philos. Trans. R. Soc. B Biol. Sci. 364 1985-1998.

Baztan, J., Carrasco, A., Chouinard, O., Cleaud, M., Gabaldon, J.E., Huck, T., Jaffres, L., Jorgensen, B., Miguelez, A., Paillard, C., Vanderlinden, J.P., 2014. Protected areas in the Atlantic facing the hazards of micro-plastic pollution: first diagnosis of three islands in the Canary Current. Mar. Pollut. Bull. 80, 302-311.

Browne, M.A., Galloway, T.S., Thompson, R.C., 2010. Spatial patterns of plastic debris along estuarine shorelines. Environ. Sci. Technol. 44, 3404-3409.

Browne, M.A., Crump, P., Niven, S.J., Teuten, E., Tonkin, A., Galloway, T., Thompson, R., 2011. Accumulation of microplastic on shorelines woldwide: sources and sinks. Environ. Sci. Technol. 45, 9175-9179.

Castaneda, R.A., Avlijas, S., Simard, M.A., Ricciardi, A., 2014. Microplastic pollution in St Lawrence River sediments. Can. J. Fish. Aquat. Sci. 71, 1767-1771.

Claessens, M., De Meester, S., Van Landuyt, L., De Clerck, K., Janssen, C.R., 2011. Occurrence and distribution of microplastics in marine sediments along the Belgian coast. Mar. Pollut. Bull. 62, 2199-2204

Cole, M., Galloway, T.S., 2015. Ingestion of nanoplastics and microplastics by Pacific oyster larvae. Environ. Sci. Technol. 49, 14625-14632.

Cole, M., Lindeque, P., Halsband, C., Galloway, T.S., 2011. Microplastics as contaminants in the marine environment: A review. Mar. Pollut. Bull. 2588-2597.

Cole, M., Lindeque, P., Fileman, E., Halsband, C., Goodhead, R., Moger, J., Galloway, T.S., 2013. Microplastic ingestion by zooplankton. Environ. Sci. Technol. 47, 6646-6655.

Costa, M.F., Ivar do Sul, J.A., Silva-Cavalcanti, J.S., Araujo, M.C.B., Spengler, A., Tourinho, P.S., 2010. On the importance of size of plastic fragments and pellets on the strandline: a snapshot of a Brazilian beach. Environ. Monit. Assess. 168, 299-304.

Dekiff, J.H., Remy, D., Klasmeier, J., Fries, E., 2014. Occurrence and spatial distribution of microplastics in sediments from Norderney. Environ. Pollut. 186, 248-256.

Desforges, J.P.W., Galbraith, M., Ross, P.S., 2015. Ingestion of microplastics by zooplankton in the Northeast Pacific Ocean. Aquat. Toxicol. 69, 320-330.

Fisner, M., Taniguchi, S., Moreira, F., Bícego, M.C., Turra, A., 2013. Polycyclic aromatic hydrocarbons (PAHs) in plastic pellets: Variability in the concentration and composition at different sediment depths in a sandy beach. Mar. Pollut. Bull. 70 (1-2), 219-226.
Frias, J.P.G.L., Sobral, P., Ferreira, A.M., 2010. Organic pollutants in microplastics from two beaches of the Portuguese coast. Mar. Pollut. Bull. 60, 1988-1992.

Galgani, F., Hanke, G., Werner, S., Oosterbaan, L., Nilsson, P., Fleet, D., Kinsey, S., Thompson, R.C., van Franeker, J., Vlachogianni, T., Scoullos, M., Veiga, J.M., Palatinus, A., Matiddi, M., Maes, T., Korpinen, S., Budziak, A., Leslie, H., Gago, J., Liebezeit, G., 2013. Monitoring guidance for marine litter in European seas. MSFD GES Technical Subgroup on Marine Litter (TSG-ML). DRAFT REPORT.

Heo, N.W., Hong, S.H., Han, G.M., Hong, S., Lee, J., Song, Y.K., Jang, M., Shim, W.J., 2013. Distribution of small plastic debris in cross-section and high strandline on Heungnam Beach, South Korea. Ocean Sci. J. 48, 225-233.

Hidalgo-Ruz, V., Thiel, M., 2013. Distribution and abundance of small plastic debris on beaches in the SE Pacific (Chile): a study supported by a citizen science project. Mar. Environ. Res. 87-88, 12-18

Hidalgo-Ruz, V., Gutow, L., Thompson, R.C., Thiel, M., 2012. Microplastics in the marine environment: a review of the methods used for identification and quantification. Environ. Sci. Technol. 46, 3060-3075.

Jambeck, J.R., Geyer, R., Wilcox, C., Siegler, T.R., Perryman, M., Andrady, A., Narayan, R., Law, K.L., 2015. Plastic waste inputs from land into the ocean. Science 347, 768-771.

Jayasiri, H.B., Purushothaman, C.S., Vennila, A., 2013. Quantitative analysis of plastic debris on recreational beaches in Mumbai, India. Mar. Pollut. Bull. 77, 107-112.

Laglbauer, B.J.L., Franco-Santos, R.M., Andreu-Cazenave, M., Brunelli, L., Papadatou, M., Palatinus, A., Grego, M., Deprez, T., 2014. Macrodebris and microplastics from beaches in Slovenia. Mar. Pollut. Bull. 89, 356-366.

Liebezeit, G., Dubaish, F., 2012. Microplastics in beaches of the East Frisian Islands Spiekeroog and Kachelotplate. Bull. Environ. Contam. Toxicol. 89, 213-217.

Lusher, A.L., McHugh, M., Thompson, R.C., 2013. Occurrence of microplastics in the gastrointestinal tract of pelagic and demersal fish from the English Channel. Mar. Pollut. Bull. 67, 94-99.

Martins, J., Sobral, P., 2011. Plastic marine debris on the Portuguese coastline: a matter of size? Mar. Pollut. Bull. 62, 2649-2653.

Mathalon, A., Hill, P., 2014. Microplastic fibers in the intertidal ecosystem surrounding Halifax Harbor, Nova Scotia. Mar. Pollut. Bull. 81, 69-79.

Mazurais, D., Ernande, B., Quazuguel, P., Severe, A., Huelvan, C., Madec, L., Mouchel, O., Soudant, P., Robbens, J., Huvet, A., Zambonino-Infante, J., 2015. Evaluation of the impact of polyethylene microbeads ingestion in European sea bass (Dicentrarchus labrax) larvae. Mar. Environ. Res. 112, 78-85.

McDermid, K.J., McMullen, T.L., 2004. Quantitative analysis of small-plastic debris on beaches in the Hawaiian archipelago. Mar. Pollut. Bull. 48, 790-794.

$\mathrm{Ng}$, K.L., Obbard, J.P., 2006. Prevalence of microplastics in Singapore's coastal marine environment. Mar. Pollut. Bull. 52, 761-767.

NOAA, 2015. Laboratory methods for the analysis of microplastics in the marine environment: recommendations for quantifying synthetic particles in waters and sediments. National Oceanic and Atmospheric Administration; U.S. Department of Commerce; Technical Memorandum NOS-OR\&R-48.

Pardos Marketing, 2006. World plastics consumption long term, 1960-2020. Retrieved January 16, 2016, from http://www.pardos-marketing.com/hot04.htm.

Plastics Europe, 2015. Plastics-the facts. An analysis of European plastic production, demand and waste data. Retrieved August 15, 2016, from http://www.plasticseurope. org/plastics-industry/market-and-economics.aspx.

Popa, M., Morar, D. Timar, A., Teusdea, A.C., Popa, D., 2014. Study concerning the pollution of the marine habitats with the microplastic fibres. J. Environ. Prot. Ecol. 15, 916-923.

Reddy, M.S., Basha, S., Adimurthy, S., Ramachandraiah, G., 2006. Description of the small plastics fragments in marine sediments along the Alang-Sosiya ship-breaking yard, India. Estuar. Coast. Shelf Sci. 68, 656-660.

Setala, O., Fleming-Lehtinen, V., Lehtiniemi, M., 2014. Ingestion and transfer of microplastics in the planktonic food web. Environ. Pollut. 185, 77-83.

Shim, W.J., Thompson, R.C., 2015. Microplastics in the ocean. Arch. Environ. Contam. Toxicol. 69, 265-268.

Thompson, R.C., Olsen, Y., Mitchell, R.P., Davis, A., Rowland, S.J., John, A.W., McGonigle, D., Russell, A.E., 2004. Lost at sea: where is all the plastic? Science 304, 838

Turner, A., Holmes, L., 2011. Occurrence, distribution and characteristics of beached plastic production pellets on the island of Malta (central Mediterranean). Mar. Pollut. Bull. 62, 377-381.

Van Cauwenberghe, L., Janssen, C.R., 2014. Microplastics in bivalves cultured for human consumption. Environ. Pollut. 193, 65-70.

Van Cauwenberghe, L., Claessens, M., Vandegehuchte, M.B., Mees, J., Janssen, C.R., 2013. Assessment of marine debris on the Belgian Continental Shelf. Mar. Pollut. Bull. 73, 161-169.

Van Cauwenberghe, L., Claessens, M., Vandegehuchte, M.B., Janssen, C.R., 2015a. Microplastics are taken up by mussels (Mytilus edulis) and lugworms (Arenicola marina) living in natural habitats. Environ. Pollut. 199, 10-17.

Van Cauwenberghe, L., Devriese, L., Galgani, F., Robbens, J., Janssen, C.R., 2015b. Microplastics in sediments: a review of techniques, occurrence and effects. Mar. Environ. Res. 111, 5-17.

van Sebille, E., Wilcox, C., Lebreton, L., Maximenko, N., Hardesty, B.D., van Franeker, J.A., Eriksen, M., Siegel, D., Galgani, F., Law, K.L., 2015. A global inventory of small floating plastic debris. Environ. Res. Lett. 10, 124006.

Vianello, A., Boldrin, A., Guerriero, P., Moschino, V., Rella, R., Sturaro, A., Da Ros, L., 2013. Microplastic particles in sediments of Lagoon of Venice, Italy: first observations on occurrence, spatial patterns and identification. Estuar. Coast. Shelf Sci. 130, 54-61.

Yang, D., Shi, H., Li, L., Li, J., Jabeen, K., Kolandhasamy, P., 2015. Microplastic pollution in table salts from China. Environ. Sci. Technol. 49, 13622-13627. 